\title{
SUNBATHED ASPEN GROW TO SHOW HOW SUNLIGHT INFLUENCES ASPEN LEAF CHANGES IN THE AUTUMN SEASON
}

\author{
S. K. Weidler ${ }^{1}$, R. Sivanpillai ${ }^{2 *}$ \\ ${ }^{1}$ University of Wyoming, Department of Geography, Laramie, Wyoming 82071, USA, ORCID: 0000-0001-7092-7782 - \\ sweidler@uwyo.edu \\ ${ }^{2}$ Wyoming GIS Center, University of Wyoming, Laramie, WY 82071, USA, ORCID: 0000-0003-3547-9464 - sivan@uwyo.edu
}

KEY WORDS: Phenology, Fall, Deciduous trees, Laramie, Active learning, TBL ABSTRACT:

Every autumn, leaves of deciduous trees change from green to other colors and eventually drop to the ground. The rate of color change is influenced by a several factors including the amount of sunlight and temperature. As part of an inquiry-based learning activity, University of Wyoming students have been recording leaf color change (\% change) and its drop date (\%) in Aspen trees (Populus tremuloides) growing in Laramie (WY) using NEON's (National Ecology Observation Network) Phenology data form. In this study, the data recorded from 2015 through 2018 were analyzed to identify trends in the rate of color change in dry and normal years. Trees that were in an area with a high amount of shade were observed to change leaf color and drop their leaves faster than those in areas that received more sun. This pattern was consistent even in years that experienced winter-like conditions in September. Findings from this multi-year study indicate that future environmental modeling projects must factor in the amount of sunlight received by aspen trees in the growing season into account.

\section{INTRODUCTION}

Aspen (Populus tremuloides) trees are found throughout North America (Grant and Mitton, 2010) and they grow in a wide range of climates, temperature, and precipitation regimes. Aspen stands are important habitat for many animals, insects, and other plants (Ripple et al., 2001; Larsen, Ripple, 2003). They serve as an important food source for deer, elk, and beavers. Beavers (Castor canadensis) use aspen for building dams and lodges (Beier, Barrett, 1987) which in turn increases species diversity near these locations. In certain geographic areas, domesticated animals (cattle and sheep) also rely on aspen as a source of nutrition (Kaufmann et al., 2013). Given their ecological and environmental impacts, it is important to track the conditions and the environments in which they grow.

Aspen follow an annual phenology cycle starting from bud burst (spring), to maximum leaf area (summer), to senescence (fall) and eventually drop their leaves in late fall (Meier et al., 2015). Timing of these events are influenced by several biotic and abiotic factors (Currit, St Clair, 2010; Hassan and Rahman, 2013). Variations in the timing of the events such as late bud burst, or early senescence will impact other species (Dreiss, Volin, 2013). Aspen plays a role in many aspects of the climate and environment, including the carbon and water cycles (Richardson et al., 2013). Hence, monitoring the phenology of aspen is important to understanding its role in the ecological system in which it is growing (Beaubien, Freeland, 2000). Knowledge of the factors affecting the length of the growing season will serve to predict relationships between the species found in the ecosystem and their impact on the environment.

The Earth's climate, along with its many ecosystems, is rapidly changing. These changes can be hard to track, even with a continual effort towards creating accurate models of the future climate. However, it is necessary to monitor the changes seen in different ecosystem and climate variables such as the levels of carbon dioxide in the atmosphere. Though the task is difficult, it is important to create the most accurate models possible. The ability to predict these changes is very useful because it provides us with the opportunity to better prepare to respond to these changes. These models require an accurate and complete understanding of all the factors that go into them, which includes the role of trees such as aspen. Tracking the variations in the phenology of individual trees could make environment and climate models more accurate than they would have been otherwise (Richardson et al., 2013). For example, phenology affects the growth season of an aspen tree by impacting its senescence, which in turn affects how much water, carbon, and other nutrients are being used by the tree. Understanding how various factors in the tree's environment impact its growing season - such as the amount of light the tree is receiving - can help to better predict how the tree will interact with its environment, and from there how it will impact global climate as a whole.
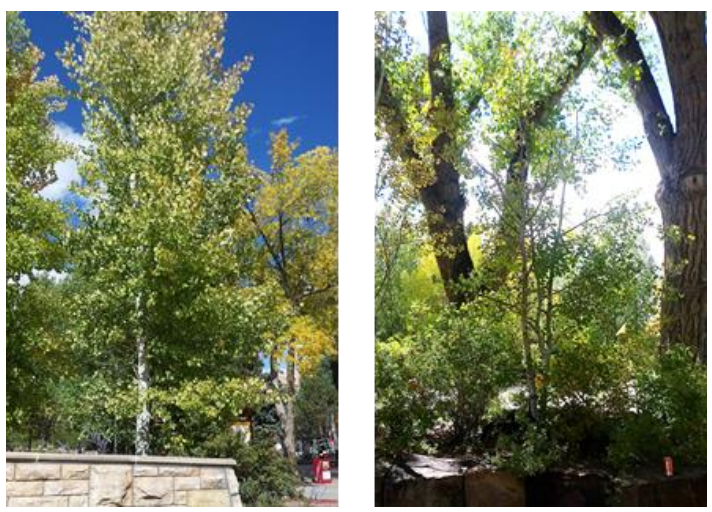

Figure 1. Some of the aspen trees growing in the University of Wyoming campus in Laramie, WY (USA). Some trees received sunlight most of the day (left) while others were shaded by trees and buildings (right).

\footnotetext{
* Corresponding author
} 
This paper describes how the amount of sunlight received by aspen trees growing in the University of Wyoming campus affects their phenology and senescence. Students enrolled in an applied remote sensing class monitored deciduous trees during the fall or autumn season (September through early November) for rates of leaf color change and drop. As part of a class exercise, students selected aspen, cottonwood, oak, and maple trees and tracked their phenology on a weekly basis. These trees were growing in open areas or under the shade of buildings and even other trees growing near them. This caused variation in the amount of sunlight received by the trees selected for observation. Some trees received sunlight only in the morning while others in the evening. In few cases, they received very little sunlight throughout the day because they were surrounded by other trees. These observations have been collected since 2015 .

The primary objective of this study was to analyze the relationship between the amount of sunlight received by aspen trees and the rates of leaf color change and drop. Every year at least one student team observed a pair of aspen trees - one growing in mostly open space and another growing in a shaded area. During the study period $(2015$ - 2018), the weather conditions were varying. The secondary objective of the study was to determine if weather conditions (precipitation and temperature), along with varying amounts of sunlight received, influenced the rate of leaf color change and drop in these trees. Findings from this study will provide valuable insights for refining ecological and environmental models.

\section{METHODS}

\subsection{Study area}

Phenology of aspen trees growing on the University of Wyoming campus located in Laramie, Wyoming (elevation: 2184 meters or 7165 feet) were analyzed in this study. Laramie is in southeastern Wyoming, to the east of the Snowy Range of the Medicine Bow Mountains. Climate conditions are warm and dry during the summer months, and cold, snowy, and windy during winter months. The growing season in the area (a period of consistent non-freezing temperatures) starts at the end of May and ends in mid-September, with freezing temperatures and snow often beginning in October. Large temperature and precipitation fluctuations are common in autumn. Maximum daily temperatures in autumn can range from $4.7^{\circ} \mathrm{C}$ to $24.2^{\circ} \mathrm{C}$.

\subsection{Data}

Students in the applied remote sensing course (BOT 5130/4130) recorded leaf color change and drop in NEON's (National Ecology Observation Network) Citizen Science Bud Burst phenology forms (Figure 2). Since observations were made in the autumn season, only data on 'Leaves changing color' and 'Leaves dropping' were recorded. Leaf color changes in the selected aspen trees were recorded as i) No leaves have changed color, ii) Early - only a few leaves have changed color $(<5 \%)$, iii) Middle - many leaves have changed color, or iv) Late - most leaves have changed color (> 95\%). Every year, students recorded their observations until all the leaves had dropped from the trees.

In addition to leaf color and drop, students were also required to record the geographic coordinates of the trees they monitored along with a short description of the locations. From these observations, we selected four sets of datasheets containing phenology records of eight aspen trees: four growing in a relatively sunny (open) area and the other four in shady areas.
Temperature and precipitation data recorded at the Laramie airport for 2015 - 2018 were downloaded from the Weather Underground (wunderground.com/history) for relating the observed phenological changes in aspen trees.

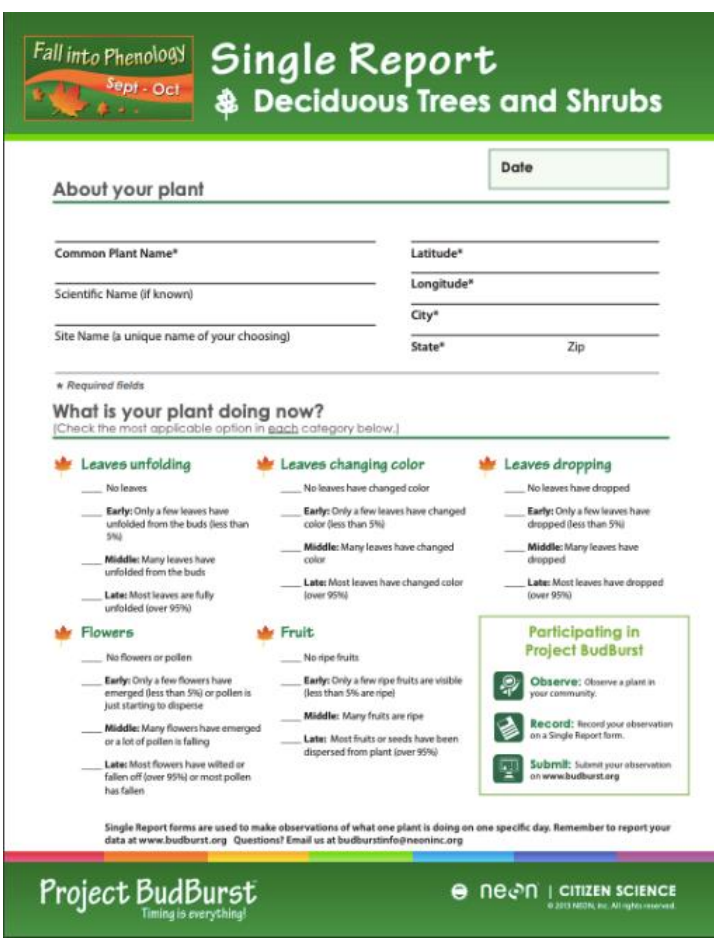

Figure 2. Phenology data form used by the students enrolled in the applied remote sensing course at University of Wyoming for tracking leaf color change and drop of deciduous trees. This form was developed by National Ecology Observation Network (NEON) as part of the Project BudBurst project.

Sudden drop in temperature, especially below $0^{\circ} \mathrm{C}$, in early fall could influence the phenology of the deciduous trees. Similarly, early season precipitation such as snowfall can stress the leaves and branches of a tree. Almost all trees growing on-campus are irrigated at least once a week along with the grass lawns, which reduced the effect of days with low amounts of precipitation.

\subsection{Interpretation}

Observation dates were converted to Day of the Year (DOY) for respective years. Next, data on 'Leaves changing color' and 'Leaves dropping' were plotted against DOY using percentage of color change or leaf drop. One plot was made for each year to visualize differences between pairs of aspen trees that grew in different amounts of sunlight.

Average minimum temperatures were plotted against each month starting from September through November. Total precipitation was also plotted for each month. Historic averages for each of the three months were also included to provide additional context for interpreting the monthly precipitation values.

Plots of leaf color change and drop were visually compared to average minimum temperature and total precipitation plots to identify patterns and potential relationships between weather and phenological patterns. These were compared because sudden drop in temperature or early season precipitation in the form of snow could influence the phenology of aspen trees. 


\section{RESULTS}

\subsection{Precipitation and Temperature Trend}

Plot of average minimum temperatures recorded for $2015-2018$ (Figure 3) revealed distinct temperature patterns for the 3 autumn months.

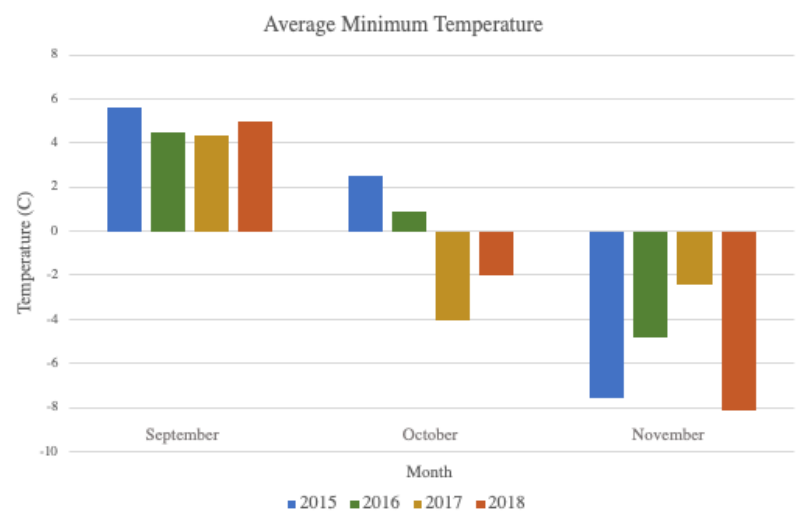

Figure 3. Monthly average minimum temperature recorded for September, October, and November 2015 - 2018.

Temperature values gradually declined every month in 2015 , 2016, and 2018 with little variations from day to day (not shown in figure). In 2017 there was a rapid decline in temperature in October and then a slight increase in November.

September 2016 had relatively more days when the minimum temperature dropped below the freezing point compared to the rest of the years analyzed in this study (Table 1).

\begin{tabular}{|l|c|c|c|c|}
\hline Month & 2015 & 2016 & 2017 & 2018 \\
\hline September & 0 & 7 & 4 & 2 \\
October & 10 & 14 & 26 & 23 \\
November & 28 & 26 & 20 & 29 \\
\hline
\end{tabular}

Table 1. Number of days in each month in $2015-2018$ fall seasons when the minimum temperature fell below $0^{\circ} \mathrm{C}\left(32^{\circ} \mathrm{F}\right)$.

In September 2015, the minimum temperature never dropped below the freezing point. October 2015 had fewer days of below freezing temperatures than October of other years (Table 1).

Monthly precipitation totals recorded for each of the months for 2015 - 2018 are shown in Figure 4. The historical average precipitation received in these months was also included for comparison.

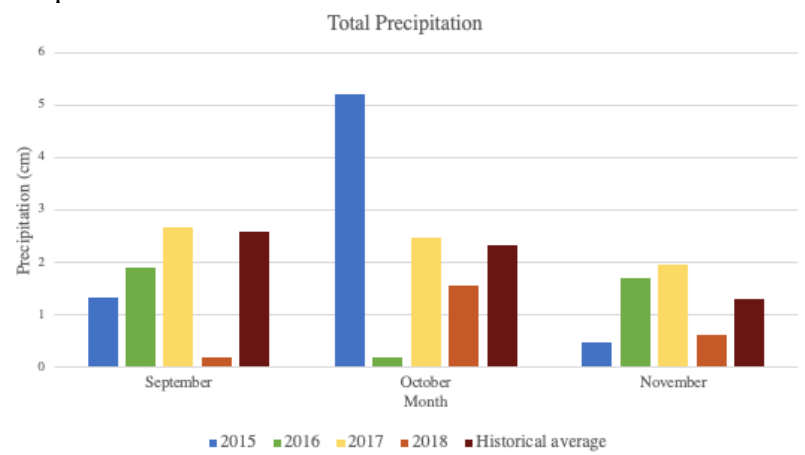

Figure 4. Total monthly precipitation recorded for September, October, and November 2015 - 2018, along with the historical averages for each month.
Laramie received average precipitation in September, October, and November 2017. September and November 2018 had very little precipitation in comparison to the average values. In October 2018 there were several large precipitation events in the beginning of the month. Compared to the historic average, there was twice the amount of precipitation in October 2015. In October 2016 there was relatively low precipitation compared to the historic average for that month.

\subsection{Leaf Color Change and Drop}

In autumn 2017, the color of the aspen leaves in the tree growing in the shaded area (blue bar in Figure 5) changed approximately a week earlier than the tree exposed to more sunlight (yellow bar). Additionally, the aspen tree growing in the shaded area (blue line) dropped its leaves a week earlier than the tree exposed to more sunlight (yellow line).

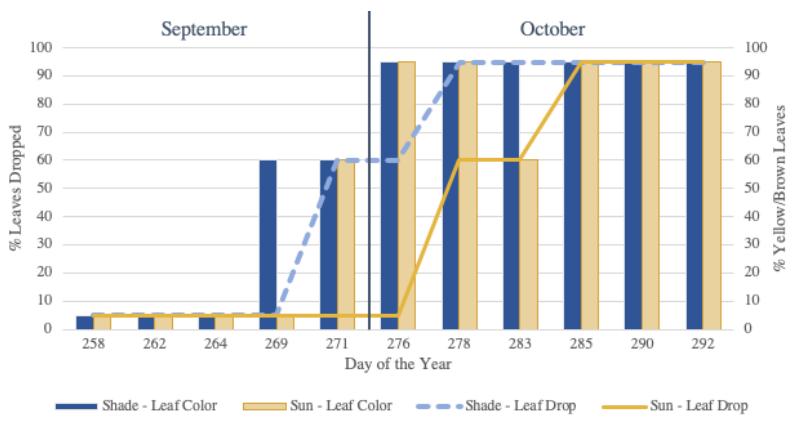

Figure 5. Temporal changes in leaf color change (bars) and leaf drop (lines) recorded in fall 2017 in the aspen trees growing in shaded (blue) and sunny (yellow) areas.

On DOY 283, this team had recorded $65 \%$ leaf color change for the sun exposed aspen tree. However, on DOY 276 and 278 this team had already recorded $95 \%$ leaf color change for the same tree. Hence the entry on DOY 283 must be transcribing error.

A similar pattern of leaf color change was noticed for a different pair of aspen trees in 2016 except for one unusual observation on DOY 272 (Figure 6). Leaves of the aspen trees that grew in shade (blue bars) changed their color more quickly in comparison to the trees that received more sunlight (yellow bars).

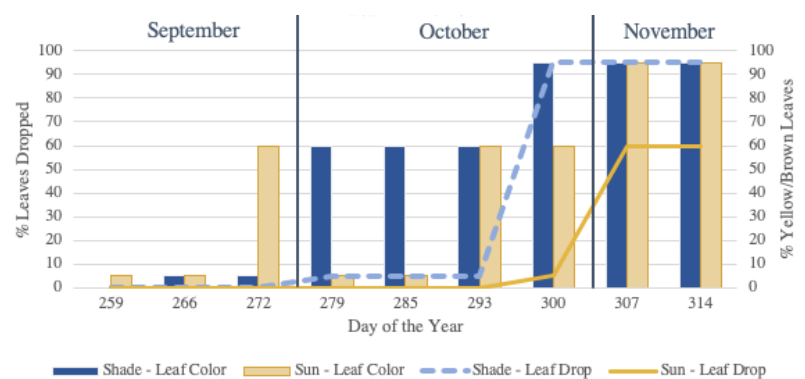

Figure 6. Temporal changes in leaf color change (bars) and leaf drop (lines) recorded in fall 2016 in the aspen trees growing in shaded (blue) and sunny (yellow) areas.

On DOY 272, the team noted that $65 \%$ of the leaves in the aspen tree receiving more sunlight changed color, but on subsequent observations (DOY 279 and 285) recorded that there was 5\% color change. Hence the observation recorded for the sunny tree on DOY 272 was excluded from interpretation. Leaves of the 
shaded tree (blue line) started to drop approximately a week earlier than the leaves of the tree receiving more sunlight (yellow lines in Figure 6). In comparison to 2017 (Figure 5), the leaves dropped later in both trees in 2016.

The pattern of leaf color change and drop in 2018 was similar to the patterns recorded in the two previous years, except both processes occurred earlier in comparison to the years before (Figure 7). The shaded tree began changing color a week earlier and was losing its leaves at a more rapid rate than the sunny tree by the end of data collection. However, the total number of observations were fewer in the 2018 season because data were not collected at the same frequency as in the 2016 and 2017 seasons.

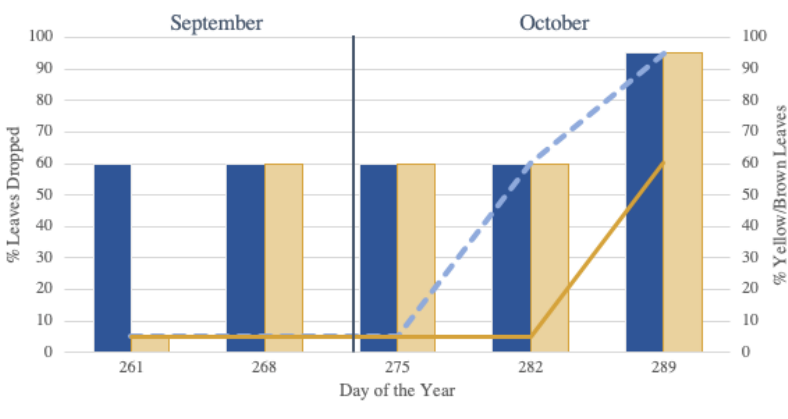

Figure 7. Temporal changes in leaf color change (lines) and leaf drop (bars) recorded in fall 2018 in the aspen trees growing in shaded (blue) and sunny (yellow) areas.

Observations recorded in 2015 (Figure 8) for another pair of aspen trees showed a delayed onset of color change (DOY 288) for both trees. Similarly, leaf drop started on DOY 302 for both trees. Coincidently, the minimum temperature never dropped below freezing point in September 2015.

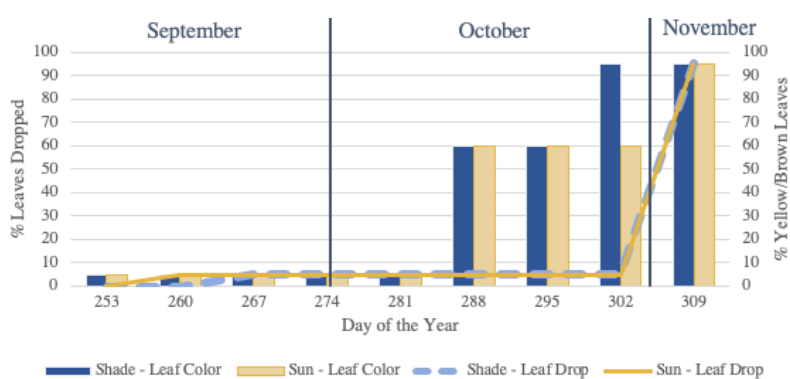

Figure 8. Temporal changes in leaf color change (bars) and leaf drop (lines) recorded in fall 2015 in the aspen trees growing in shaded (blue) and sunny (yellow) areas.

October 2015 had fewer days with the minimum temperature dropping below the freezing point than other years. Despite the warmer temperature recorded in the first two months, the shaded tree changed its color one week before the sunny tree. However, both trees dropped their leaves at approximately same time.

\section{DISCUSSION}

\subsection{Multi-year phenology trends}

Aspen trees that received relatively less sunlight in spring and summer changed their leaf color and dropped their leaves earlier in the year than those trees that received more sunlight. This pattern was consistent in the data collected by students enrolled in this course over four years $(2015$ - 2018), despite the differences in data collection dates and frequency between groups.

This trend was also consistent under varying weather conditions each year. Despite having different precipitation and day-to-day temperature patterns every year, trees in the shade always lost their leaves and changed color more rapidly than their sunnier counterpart.

\subsection{Data collection and interpretation}

Interpreting data collected in multiple years by different groups of students posed some challenges. Not all groups collected data on the same day of the week and some groups even collected data more than once a week. Few of the groups randomly collected data on their trees rather than following once-in-a-week pattern of other groups. In some cases, the frequency of data collection decreased as fall senescence set in. If more time had passed between two consecutive data collections, it is possible to miss the rate of leaf color change or drop. Within the same year, some teams had recorded 11 observations, and a few had recorded only three. Data recorded on random days for few weeks would have missed some phenological stages. In this study, we excluded data collected for fewer weeks. If all teams had recorded sufficient data, phenology data from more pairs of trees could have been analyzed.

For future years, all teams must be required to collect data for both trees at same interval-once a week for example, and preferably on the same day of the week. Once senescence sets in, teams must collect data twice a week to capture detailed phenological changes. Instructors must require students to submit the completed forms every week to check for any inconsistencies. This would allow students to correct their data through additional observations. Consistent data collection between groups and years will enable direct comparisons of changes throughout senescence.

The phenology data form developed by NEON has only four categories of leaf color changes and drop. Limiting the responses to four categories introduced some ambiguity. For example, each group could have interpreted the categories 2 (few), 3 (many), and 4 (most) slightly differently. In some groups, students took turns collecting data which introduced errors. For example, in one week a member would record a value of Middle $(60 \%$ change) for leaf color change, while next week another member would record a value of Early (5\% change). To address these inconsistencies, it is important to have consistent definition for each category in order to minimize variations between groups collecting data in the same and different years.

Only very few groups recorded additional information such as the amount of sunlight received in their data forms. Since shady trees receive different amounts of sunlight, their leaf color and leaf drop phenology differ from trees growing in sunnier locations. The groups that recorded the amount of sunlight did so in order to identify light level as the factor of comparison between trees.

NEON forms do not collect this information because their primary purpose is to record the phenology of individual trees. In future years, student teams must record additional details about the shady trees. For example, if a tree receives some sunlight for a short amount of time in the morning or evening it must be recorded as part of the summary observations. 
We recommend that additional information on temperature and precipitation be recorded in the weekly datasheets. This information will be helpful for interpreting changes in leaf color and drop, especially when abrupt changes occur. For example, when the temperature suddenly drops or if the study area receives early fall season snow, this information will be valuable to interpret any rapid changes in leaf color or drop. This information can be used to account for the effect of weather conditions on the same trees in multiple years.

In this study, phenology data for four different pairs of aspen trees were analyzed for as many years. In the future, phenological changes in one pair of aspen trees must be tracked over multiple years. This will provide more insights about how the same pair of trees changed their leaf color in different years.

\subsection{Tree location data}

Some groups recorded the geographic coordinates more precisely than others. Also, many teams used their smart devices (phones) to record the geographic coordinates. The precision of these locational data entered in the data forms was not sufficient to locate all the trees, especially if they were growing near other aspen trees of similar size or age. However, many groups had included brief description regarding the location in addition to the coordinates. To reduce ambiguity in future studies, teams must include an identification tag before taking photos of the tree. This can allow future teams to precisely locate the trees for multi-year studies.

\subsection{Other Patterns}

In fall 2015 , the shady aspen tree monitored by one of the groups was surrounded by other aspen trees, i.e., grew in a cluster. This group observed that this tree changed leaf color quicker and dropped its leaves earlier than a tree that grew by itself away from other trees. This points out that additional factors, such as proximity to other aspen trees, must be considered in the future. It would be useful to identify whether growing in a group is something that impacts aspen every year regardless of temperature and precipitation. We recommend that students must be encouraged to choose this factor for data collection in future semesters.

In the future, the phenology data for trees growing in varying sunlight levels could be expanded to other species of trees growing on the University of Wyoming campus. There are several cottonwood trees (Populus sect. Aigeiros) of different age and size, that are growing in different light conditions which could result in a rich set of phenology data. It would be important to examine whether other species follow a similar or different trend of earlier senescence in trees which have grown in areas with less exposure to sunlight.

\section{CONCLUSIONS}

Phenology data of pairs of aspen trees recorded from 2015 to 2018 indicate that the amount of sunlight received by aspen trees influenced color changes of leaves and rate of leaf drop. This pattern was consistent across all four years though there were variations in data collection dates and frequency within and across these years.

Warmer fall seasons (2015) as measured by fewer number of days where the minimum temperature dropped below the freezing point delayed the changes by few weeks.
Budburst forms developed by NEON are able to track major phenological changes but adding a few more categories for leaf color and drop would increase the precision of the recorded data.

Including additional information about the trees such as the amount of sunlight they receive during the day, their proximity to other trees, and photos with recognizable markers will enable more detailed interpretation of phenology data. This will also enable future teams to precisely locate the same pairs of trees for multi-year observations.

\section{ACKNOWLEDGEMENTS}

First author acknowledges the WyomingView internship opportunity that made this study possible. Additionally, thanks to the Wyoming Geographic Information Science Center (WyGISC) and the Department of Geography at the University of Wyoming for providing the funding to travel and present this study at the ASPRS GeoWeek 2020 conference.

This material is based upon work supported by the U.S. Geological Survey under Grant/Cooperative Agreement No. G18AP00077 to the second author. The views and conclusions contained in this document are those of the authors and should not be interpreted as representing the opinions or policies of the U.S. Geological Survey. Mention of trade names or commercial products does not constitute their endorsement by the U.S. Geological Survey. This manuscript is submitted for publication with the understanding that the United States Government is authorized to reproduce and distribute reprints for Governmental purposes.

\section{REFERENCES}

Beaubien, E.G., Freeland, H.J., 2000. Spring phenology trends in Alberta, Canada: links to ocean temperature. International Journal of Biometeorology, 44:53-59. DOI:

Beier, P., Barrett, R.H., 1987. Beaver Habitat Use and Impact in Truckee River Basin, California. The Journal of Wildlife Management, 51(4): 794-799.

Currit, N., St Clair., S.B., 2010. Assessing the impact of extreme climatic events on aspen defoliation using MODIS imagery. Geocarto International. 25(2): 133-147. DOI: 10.1080/10106040903051975.

Dreiss, L.M., Volin, J.C., 2013. Influence of leaf phenology and site nitrogen on invasive species establishment in temperate deciduous forest understories. Forest Ecology and Management, 296: 1-8. DOI: 10.1016/j.foreco.2013.01.031.

Grant, M., Mitton, J., 2010. Case Study: The Glorious, Golden, and Gigantic Quaking Aspen. Nature Education Knowledge 3(10):40.

Hassan, Q.K., Rahman, K.M., 2013. Applicability of remote sensing-based surface temperature regimes in determining deciduous phenology over boreal forest. Journal of Plant Ecology, 6(1): 84-91. DOI: 10.1093/jpe/rts010.

Kaufmann, J., Bork, E.W., Alexander, M.J., Blenis, P.V., 2013. Habitat selection by cattle in Foothill landscapes following variable harvest of aspen forest, Forest Ecology and Management, 306: 15-22. DOI: 10.1016/j.foreco.2013.06.004. 
Larsen, E.J., Ripple W.J., 2003. Aspen age structure in the northern Yellowstone ecosystem: USA. Forest Ecology and Management, 179: 469-482. DOI: 10.1016/S03781127(02)00532-7.

Meier, G.A., Brown, J.F., Evelsizer, R.J., Vogelmann, J.E., 2015. Phenology and climate relationships in aspen (Populus tremuloides Michx.) forest and woodland communities of southwestern Colorado, Ecological Indicators, 48: 189-197. DOI: 10.1016/j.ecolind.2014.05.033.

Richardson, A.D., Keenan, T.F., Migliavacca, M., Ryu, Y., Sonnentag, O., Toomey, M., 2013. Climate change, phenology, and phenological control of vegetation feedbacks to the climate system. Agricultural and Forest Meteorology, 169:156-173. DOI: 10.1016/j.agrformet.2012.09.012.

Ripple, W.J., Larsen, E.J., Renkin, R.A., Smith, D.W., 2001. Trophic cascades among wolves, elk and aspen on Yellowstone National Park's northern range, Biological Conservation, 102(3) 227-234. DOI: 10.1016/S0006-3207(01)00107-0. 